\title{
Pharmacist interventions for obesity: improving treatment adherence and patient outcomes
}

This article was published in the following Dove Press journal:

Integrated Pharmacy Research and Practice

8 July 2015

Number of times this article has been viewed

\author{
Melanie A Jordan \\ Jonathan Harmon \\ College of Pharmacy - Glendale, \\ Midwestern University, Glendale, AZ, \\ USA
}

Correspondence: Melanie A Jordan Department of Pharmaceutical Sciences, College of Pharmacy - Glendale,

Midwestern University, 19555 North

59th Avenue, Glendale, AZ 85308, USA

Tel + I 6235723578

Fax + I 6235723565

Emailmjorda@midwestern.edu

\begin{abstract}
Obesity is currently a worldwide pandemic, with overweight (body mass index $[\mathrm{BMI}] \geq 25 \mathrm{~kg} / \mathrm{m}^{2}$ ) and obesity (BMI $\geq 30 \mathrm{~kg} / \mathrm{m}^{2}$ ) estimated at $35 \%$ and $12 \%$ of the global adult population, respectively. According to data collected from the United States National Health and Nutrition Examination Survey, approximately $68.8 \%$ of US adults are overweight or obese. Additionally, a large burden of health care costs can be attributed directly to obesity as well as multiple, potentially preventable, comorbidities such as cancer, cardiovascular disease, and diabetes. As a result, national and international organizations, such as the US Centers for Disease Control and World Health Organization, have made halting the rise of the obesity epidemic a top priority. Pharmacists, commonly considered one of the most trustworthy and accessible health care professionals, are ideally situated to provide counseling for weight and lifestyle management. This review presents examples of pharmacist-led as well as collaborative practices that have been somewhat successful in educating and monitoring patient progress in attaining weight-loss goals. Common barriers and potential solutions to administration of lifestyle counseling and monitoring programs, such as limited pharmacist time and resources, lack of expertise and/or confidence in program administration, and patient perception and awareness, are also discussed.
\end{abstract}

Keywords: pharmacy, obesity, counseling, weight loss, lifestyle management

\section{Introduction}

Obesity is currently a worldwide pandemic. Of the world's population, an estimated $35 \%$ of adults are overweight - defined by the World Health Organization (WHO) as a body mass index (BMI) of $\geq 25 \mathrm{~kg} / \mathrm{m}^{2} .{ }^{1}$ Globally, an estimated $12 \%$ of adults are obese $\left(B M I \geq 30 \mathrm{~kg} / \mathrm{m}^{2}\right)$, half of whom live within just a handful of countries, including the United States of America, People's Republic of China, India, Russia, Brazil, Mexico, Egypt, Germany, Pakistan, and Indonesia. ${ }^{1,2}$ In Europe, more than $50 \%$ of adults are overweight and $20 \%$ of men and $23 \%$ of women are obese. ${ }^{3}$ Similar trends are seen in data collected from the United States National Health and Nutrition Examination Survey, where approximately $68.8 \%$ of adults are overweight or obese. ${ }^{4-8}$

The prevalence of obesity worldwide nearly doubled from the 1980s to 2008, and although the rate of increase has slowed, obesity remains a major global health concern. ${ }^{1,8}$ Globally, the annual cost of obesity-related diseases has reached $\$ 2$ trillion according to a recent report by McKinsey Global Institute. ${ }^{9}$ In Europe, the WHO estimates that up to $6 \%$ of health care expenditures are due to obesity and obesityrelated diseases. ${ }^{10}$ Similar estimates are observed in the United States, with total health expenditures projected to reach $\$ 344$ billion by 2018 and $16 \%-18 \%$ of health care 
costs by $2030 .^{11,12}$ The WHO estimates that $44 \%$ of diabetes cases, $23 \%$ of ischemic heart disease cases, and 7\%-41\% of certain cancers may be attributed to obesity. ${ }^{12-14}$ Thus, a large burden of health care costs can be attributed directly to obesity, but more significantly to multiple, potentially preventable, comorbidities.

The rise in obesity can be attributed to multiple factors, most notably modern lifestyles, which allow for easy access to inexpensive unhealthy foods, sedentary lifestyle, and environmental factors that limit access to healthy diet and exercise management. ${ }^{15,16}$ Effective management of the obesity pandemic requires the promotion and fundamental acceptance of healthy lifestyle habits, which in turn depend upon the availability of resources such as affordable nutritious food options and access to venues that promote exercise. ${ }^{15}$ In addition, counseling and guidance by health care professionals is necessary for disease state prevention and treatment. The WHO Global Action Plan for the Prevention and Control of Noncommunicable Diseases outlines several objectives to be attained by 2020, including increasing physical activity; decreasing the risk of premature mortality from cardiovascular disease, cancer, diabetes, and chronic respiratory diseases; and halting the rise in diabetes and obesity. ${ }^{17}$ Specifically, Objective 4, which focuses on strengthening health care systems, calls for the development of career tracks in the health care professions, including pharmacy, that focus on noncommunicable diseases. A position statement by the American Society of Health-System Pharmacists also recommends increased counseling by pharmacists to help obese patient manage lifestyle modifications. ${ }^{18}$ Because community pharmacists are generally easily accessible to patients at locations throughout the community on a walk-in basis (ie, no appointment is required), they might serve as an alternative source for lifestyle and weight-loss counseling. Previously, pharmacists have demonstrated success in disease state management, often in comorbid diseases, such as diabetes, hyperlipidemia, and hypercholesterolemia. ${ }^{19-22}$ In addition, pharmacists receive a comprehensive education that covers disease state etiology, risk factors, prevention, management, and treatment, which gives them a strong foundation for providing lifestyle management counseling. ${ }^{23}$

\section{Pharmacist interventions in overweight and obesity}

Several studies have investigated potential models for pharmacist involvement in the provision of lifestyle and weight-loss management either alone or in collaboration with other health care providers. In a recent study by
Um et al, health care providers in Australia - including pharmacists, dieticians, exercise physiologists, physicians, and a psychiatrist - were interviewed for insight into the development of a best practice model for pharmacy-based weight management services. ${ }^{24}$ In general, the participants believed that pharmacists were well suited to delivering weight management services, especially given their regular contact with patients. Participants felt that pharmacists were already well trained to perform basic physical assessments such as weight, waist circumference, blood glucose monitoring, and pharmacotherapy counseling, while additional training could be easily obtained for services that would encompass dietary counseling, guidance on physical activity, and behavioral counseling. The survey respondents also noted several barriers to implementation of pharmacist-based weight-loss counseling, including the need for additional training and changes in current pharmacy practice models related to reimbursement for services and facility design that hinder effective, individualized counseling.

\section{Weight-loss management}

There have been several reports in the literature on pharmacybased efforts for weight and lifestyle management. Programs that have been developed exist either within community pharmacies alone or as part of collaborative agreements between pharmacists, physicians, and other health care providers..$^{25-35}$

\section{Pharmacy-based weight management programs}

In one study, pharmacists in Scotland were trained by dieticians to administer the Counterweight Program as part of the Keep Well project designed to encourage middle-aged adults (40-64 years old) at high risk for cardiovascular disease to improve their health. ${ }^{33} \mathrm{~A}$ small number $(\mathrm{n}=18)$ of pharmacies were enrolled in geographical areas with limited access to general practitioners offering the Counterweight Program. Overall, 314 patients $(68.6 \%)$ completed the program, which required nine separate 10-30-minute visits over a 12-month period in which the pharmacist or pharmacy assistant counseled patients on a prescribed eating plan and weight management strategies and measured patient weight. At the end of the 12-month study period, $41.6 \%$ of enrolled patients who attended all program meetings lost $\geq 5 \%$ of initial body weight; however, the percentage decreases to $10.2 \%$ when accounting for patients who remained in the program but did not attend all meetings. Although follow-up data that recorded weight maintenance were not obtained, this paper demonstrates that pharmacy-assisted weight-loss 
management programs may be successful for some patients given that continued adherence to program interventions can be maintained.

A small pilot study of 12 patients was performed in a community pharmacy situated within a county government facility, which investigated the administration of 6-month, 14-visit series of 15-minute visits focused on educating enrolled patients about diet, exercise, and nutrition. ${ }^{28}$ The program was modeled to fit the guidelines of the Centers for Medicaid and Medicare Services' Decision Memo for Intensive Behavioral Therapy for Obesity. ${ }^{29}$ Weekly (during the first month) or biweekly visits were led by a pharmacy resident; height, weight, waist circumference, body fat composition, and nutritional history were assessed at the first and last sessions. Overall, eleven of the 12 enrolled subjects completed the program: significantly decreased body weight $(P<0.001)$, visceral fat $(P=0.024)$, waist circumference $(P=0.002)$, and BMI $(P<0.001)$ relative to baseline. However, this study was limited in patient enrollment and demographics, and the results should be interpreted with caution.

\section{Collaborative practice weight management programs} One noted limitation of pharmacist-led obesity and lifestyle management counseling is the lack of time many pharmacists face as their roles expand. ${ }^{24,34}$ Similar challenges are observed in other health care professions. Therefore, formation of collaborative practice models may help to alleviate practitioner time constraints while promoting patient compliance with the ongoing support provided in the pharmacy setting between physician office visits.

The Healthy Habits weight-loss program currently administered at Auburn University, a self-insured institution, was developed to serve the college campus through a stand-alone pharmaceutical care center. ${ }^{30}$ Pharmacy faculty, students, and residents provide continued support for patients enrolled in the program to help reach and maintain goal weight. Consent to obtain medical records and to contact the primary care physician is also obtained from patients enrolling in the program. Initial patient intake interviews consist of a complete medical, family, and social history and physical assessment, including weight, height, body composition analysis, waist circumference, blood pressure (BP), heart rate, and lipid panel. Additionally, risk of weightrelated complications is assessed and patients are screened for disease states and current medications that could cause weight gain or hinder weight loss. Finally, care center staff develop nutrition and exercise plans. Patients are encouraged to attend biweekly follow-up meetings to assess progress and provide additional education and support. Through retrospective analysis of program data from the first 5 years of program administration $(n=289)$, over $13 \%$ of enrolled patients achieved greater than $10 \%$ weight loss. However, the authors comment that although several patients achieved their ultimate weight-loss goals, all relapsed during the maintenance phase of the program.

The Lifestyle Challenge program, a collaborative practice including a physician with nutrition expertise, a pharmacist, and a behavioral psychologist, was performed at an outpatient university setting in New York State. ${ }^{32}$ The program was aimed at adults with a BMI $>27 \mathrm{~kg} / \mathrm{m}^{2}$ and with or at a high risk of one or more obesity-related comorbidities. Patients enrolled in the fee-for-service program attended 20 weekly, 1-hour diet, exercise, and behavioral modification educational sessions along with ongoing clinical assessments. Midpoint and final review occurred at 10 weeks and 20 weeks, respectively. Initial intake interviews were conducted by the physician and psychologist and included complete medical and medication history, baseline laboratory values, and psychological assessments, including the Short Form 36 health status measure, Gormally Binge Eating Scale, and Beck Depression Inventory. Involvement of the pharmacist included routine clinical assessments (eg, weight, height, waist circumference, and medication review) as well as data scoring and analysis. Ninety patients initially enrolled in the program, with $59(65.6 \%)$ completing all 20 weeks. Compared to baseline, an average of $4.8 \%$ loss of body weight $(P=0.052)$ was observed (range $5.9 \%$ weight gain to $17.1 \%$ weight loss). Significant improvement in psychological assessments was also observed. Results from this study suggest that collaborative, multidisciplinary practices involving pharmacists can promote successful, albeit limited, weight management for obese patients.

Other examples of potential collaborative practice models exist. At one family practice site with limited resources available to accommodate demand for increased services, a pharmacist was recruited to perform Medicare's Annual Wellness Visit, which included health risk assessments, medication therapy management, and assessment of the need for appropriate health screenings, immunizations, and lifestyle issues. ${ }^{34}$ This successful collaborative practice allowed for increased accommodation of patient needs in this area, improved practice site revenue, and enhanced incorporation of the pharmacist as part of the health care team. In another comprehensive meta-analysis of 298 studies, the success of pharmacist-provided direct patient care related to multiple 
outcomes was examined. ${ }^{27}$ Outcomes related to safety and therapeutics were found to be favorable following pharmacistled hemoglobin $\mathrm{A}_{1 \mathrm{c}}$, low-density lipoprotein cholesterol, BP, patient education, and quality of life interventions, all of which are directly relatable to the management of overweight and obesity. In another pilot study, pharmacists were educated by a pharmacist and physician specializing in obesity during a 1-day training course regarding disease pathology and treatment and were trained in physical assessment techniques. ${ }^{31}$ Thereafter, patients who were being treated at a university teaching hospital-based outpatient nutrition clinic and prescribed the lipase inhibitor orlistat were asked to participate in biweekly monitoring sessions with trained pharmacists in their local community pharmacy as an adjunct to clinic follow-up visits every 4-6 weeks. Control subjects attended only follow-up clinic appointments and did not receive any pharmacist interaction beyond the dispensing of medication. Overall, patients who received pharmacist intervention continued treatment with orlistat significantly longer $(P<0.05)$ than patients without intervention. Twice as many patients receiving pharmacist counseling $(40 \%)$ compared to the control subjects (20\%) reached a weight-loss goal of $>3 \%$ of initial body weight, although the overall difference in weight loss was not significant between the two groups. This study is relatively limited since only 30 patients were initially enrolled, but it does suggest that continued monitoring and counseling of patients intermittently during drug therapy may improve patient outcomes. Interestingly, when comparing reasons for discontinuation of orlistat therapy, over half of patients in the control group (9/15) cited inadequate weight loss or failed to return to the clinic, whereas none of the pharmacist interaction group cited these reasons. This again suggests that ongoing pharmacist counseling might help motivate patients to continue both drug therapy and physician interaction to attain weight-loss goals. In addition, this study is an example of how obesity and lifestyle counseling can be paired with medication dispensing to promote weight loss in patient populations.

An extensive and holistic collaborative program was developed in Australia, in which a healthy lifestyle program was administered to a small number of patients $(n=40)$ with chronic disease risk factors after hours in a community pharmacy. ${ }^{35}$ The program consisted of a comprehensive medication review by the pharmacist, free gym membership, access to cooking classes, supermarket tours, and nutritional counseling from a registered dietician. Selected patients were also provided with prepaid visits to a general practitioner and help in establishing a home vegetable garden. Body weight, waist circumference, and fruit and vegetable consumption were measured at baseline and at the end of the 1-year program. At the end of the study, patients significantly $(P<0.001)$ decreased weight and waist circumference and significantly $(P<0.001)$ increased fresh fruit and vegetable consumption as well as weekly physical activity compared to baseline. This holistic approach to wellness appears to be a good model, but feasibility depends on willingness of the collaborators to contribute time. In addition, this model requires the collaboration of a great number of different practitioners and resources, which makes it difficult to isolate the benefits of individual pharmacists in interventions concerning obesity, but serves to show that when used correctly, pharmacists can aid and help in interventions for obesity.

\section{Management of diseases related to overweight and obesity}

Pharmacist interventions in disease states often comorbid with obesity have been well documented in the literature. Such interventions include drug therapy management and lifestyle modifications in disease states like cardiovascular disease and type 2 diabetes. ${ }^{20,22,36-39} \mathrm{Often}$ part of the documented interventions in these studies includes counseling and education aimed at improving factors that are also related to obesity, such as increased physical activity and adoption of healthy nutritional plan. For example, in a retrospective medical record review, Stading et al found that newly diagnosed type 2 diabetics or diabetic patients starting on insulin therapy were more successful at lowering $A_{1 \mathrm{c}}$ values when intervention teams included a pharmacist along with a physician and a dietician compared to teams with only a physician and a dietician. ${ }^{40}$

A cross-sectional survey of 234 patients assessed what type, if any, of follow-up information regarding lifestyle modification was received, after being prescribed lipidlowering medications obtained either in a hospital or through a community pharmacy. ${ }^{37}$ Approximately three-fourths of respondents received information about lifestyle modifications aimed at lowering lipid levels, nearly all of whom (83.8\%) stated that information was received from their physician. However, less than half continued to receive follow-up information and very few received any lifestyle counseling from their pharmacist. When patients did receive follow-up information, they were more likely to be actively involved in lifestyle modifications (eg, diet and exercise) to lower their serum lipid levels. Based on this study, it would seem beneficial to engage pharmacists in ongoing lifestyle counseling in between physician visits, in order to help potentiate patient engagement in their own health maintenance. 
In another study, patients were provided with general lifestyle management counseling by a pharmacist. ${ }^{41}$ In the prospective cohort study, pharmacists $(n=28)$ were not formally trained, but were provided with various modules that they were encouraged, but not required to review. At baseline cholesterol, triglycerides (TG), BP, fasting blood glucose (FBG), BMI, and waist circumference were measured. Patients $(n=90)$ interested in the program were allowed to self-select the pharmacist providing the training during monthly, 5-60-minute wellness visits. Wellness topics - which included education, goal setting, and monitoring - were aimed to improve health in four disease state categories: high cholesterol (using the Framingham risk assessment), hypertension (BP $>120 / 80 \mathrm{mmHg}$ ), diabetes (FBG $>100 \mathrm{mg} / \mathrm{dL})$, and weight $\left(\mathrm{BMI}>24.9 \mathrm{~kg} / \mathrm{m}^{2}\right) .{ }^{42}$ Following a 12-month program, which was completed by 81 patients $(90 \%)$, cholesterol (total, low-density lipoprotein, and high-density lipoprotein) and BP all significantly improved. However, there was no significant change in TG, FBG, BMI, or waist circumference. Although the study was limited in scope with regard to patient demographics and lack of normalization of pharmacist training programs, it suggests that ongoing pharmacist interactions can improve some health parameters. Additionally, data from this study were presented as an aggregate of all patients; however, only $63 \%$ of enrolled patients were placed in the weight category, so it is difficult to determine if weight loss was greater in this subpopulation compared to the entire study group. Additionally, pharmacists were provided with limited training, which may have hindered effective counseling and limited successful outcomes.

A similar study by John et al provided patients $(n=56)$ with a self-insured workplace-based pharmacist-led program to increase wellness for individuals at high risk for cardiovascular disease. ${ }^{43}$ Education was focused on improving cardiovascular health but included diet and exercise counseling as interventions. Pharmacists provided disease state and lifestyle education sessions approximately every 4-8 weeks for a minimum of eight visits in the first year and six visits in the second year. Pharmacists communicated with primary care physicians to obtain patient laboratory or clinical data records and/or to recommend changes to pharmacotherapy. Billing data were used to examine changes in BP, cholesterol, $\mathrm{TG}$, weight, and BMI retrospectively using the patients as their own controls. At the end of a 3-year study period, a significant improvement in systolic and diastolic BP was observed $(P<0.05)$ overall, although patients with diabetes did not significantly decrease diastolic BP. However, no significant reductions in weight, BMI, cholesterol, or TG were observed. The study is limited in patient enrollment, lack of a control group, and inability to differentiate between the effect of patient education and pharmacotherapy on outcomes. The main goal of the study was to improve cardiovascular health through both education and pharmacologic intervention as necessary, rather than strictly a focus on weight loss, and therefore, the results may not extrapolate to treatment of obese/overweight populations.

\section{Barriers to implementing pharmacist-led lifestyle management}

Given the evidence, utilization of pharmacists as sources of ongoing monitoring and education for lifestyle modification, with the end goal of weight reduction, appears to have some benefit. However, as the role of the pharmacist continues to expand to include wellness and prevention in addition to drug therapy and disease state management, several barriers to expanded pharmacy services have arisen, including lack of time, space, education, or reimbursement. ${ }^{44-50}$ One survey of 139 pharmacists in Texas revealed that pharmacists only rarely or sometimes counsel on weight and lifestyle management, with diet and exercise and drug therapy counseling being most common. ${ }^{45}$ Frequency of counseling was directly and positively correlated to pharmacist comfort level with counseling on the topic, confidence in their knowledge in the topic, and the perceived effectiveness of counseling. In a similar cross-sectional study performed in Kuwait, 220 surveyed community pharmacists responded that they counseled sometimes to most of the time on obesity management and were neutral to comfortable with performing this service. ${ }^{44}$ However, over $70 \%$ of these pharmacists perceived that major barriers to effective obesity management by pharmacists included lack of awareness by patients of the service and overall nonadherence by patients.

\section{Pharmacist knowledge of obesity and weight-loss management}

Frequently, lack of knowledge of obesity and its treatment or lack of comfort in providing weight management services are cited as barriers to pharmacist-led interactions. In a survey of US colleges of pharmacy curricula in 2007, it was found that few schools incorporated recommended lifestyle modification and other public health promotion topics in their curriculum. ${ }^{51}$ However, at the time the study was published, the new Accreditation Council for Pharmacy Education Standards 2006 had only recently become effective (July 2007). ${ }^{52}$ Standard 12 - Professional Competencies and Out- 
come Expectations - requires that pharmacy curricula train students to promote health, wellness, and disease prevention through interprofessional teams by developing and implementing population-specific and evidence-based disease management programs and protocols. Appendix B of the Standards also notes that students should be knowledgeable about interpretation of laboratory tests and assessments. The newest set of standards (Standards 2016) has recently been approved and is due for implementation in $2016 .{ }^{53}$ Standard 2 - Essentials for Practice and Care - continues to require students learn to design and implement health, wellness, and prevention programs, while Standard 4 - Personal and Professional Development - aims to prepare students to engage in innovation and entrepreneurship using creative thinking skills. Together, these newly stated standards suggest that future US pharmacy students will be prepared to offer patient services, including weight-loss and lifestyle management. Additionally, Appendix 1 of Standards 2016 calls for students to not only have the knowledge to interpret laboratory tests but also be able to perform health screenings, laboratory data interpretations, and physical assessments. Under topics suggested for Public Health curricula, students should be knowledgeable about both national and community-based public health programs and able to implement activities that advance public health and wellness. With the revision of current curricula to meet the new standards, future pharmacy graduates should have a stronger knowledge and skills in physical assessment and laboratory value analysis and counseling skills are needed to develop and implement community-based wellness programs. Current pharmacists can benefit by participating in educational opportunities such as continuing education programs and seminars aimed at weight loss and obesity topics and wellness and health promotion, and training in administering and interpreting point-of-care testing and physical assessment. ${ }^{54}$

\section{Pharmacy resources and time}

Other major barriers to effective administration of wellness programs are lack of pharmacist time and appropriate counseling space. ${ }^{24,46,48,49}$ Commonly, pharmacies are designed with limited space for pharmacist-patient interactions, focusing more on the traditional dispensatory role of the pharmacist. However, with increased focus on patient care, some pharmacy chains are beginning to turn to wellness models focused on shifting the pharmacist role to counseling rather than dispensing, sometimes physically placing the pharmacist up front rather than behind the counter. ${ }^{55,56}$ Should this model prove successful, its widespread imple- mentation may free up pharmacist time, improve pharmacist accessibility, and allow for more personalized and focused patient interactions. Many pharmacies have also begun to build clinic services into their space, in which patients with minor medical issues can be seen by nurse practitioners and physician assistants for diagnosis and treatment or for monitoring and management of disease states (eg, Walgreens Take Care Clinic, CVS Minute Clinic, Rite Aid Now Clinic, and others). Shared use of clinic space and/or collaboration with clinic providers would also increase resources for pharmacistled educational sessions and wellness coaching.

Studies regarding pharmacist workload indicate that dispensing of medication accounts for the majority of time spent on work activities, with little time left for patient interaction and counseling. For example, a cross-sectional study of US pharmacists in various practice settings was performed using survey questions from the 2004 National Pharmacist Workforce Study. ${ }^{57}$ Community practice pharmacists generally perceived a disconnection between the amount of time spent on counseling patients compared to their desired amount of time on this activity. In 2002, only approximately $19 \%$ of US pharmacist time was devoted to counseling activities, with the majority of time spent on dispensing and managerial roles. ${ }^{58}$ In a joint Kaiser Permanente/USC Patient Consultation Study, the pharmacist time spent on various counseling and problem-solving tasks was investigated. Overall, an average of only 3 minutes is spent counseling patients in cases involving monitoring of adverse effects, duplicate therapy, and compliance issues; presumably, less time is spent counseling patients in cases that do not require close monitoring. ${ }^{59}$

It may be possible to increase pharmacist counseling time by increasing involvement of technicians and students in the dispensing role, although more evidence is needed to determine if such a model would be effective. ${ }^{60}$ Additionally, students and community pharmacy residents may be a valuable resource to assist the pharmacist in developing, running, and maintaining weight-loss and other wellness programs. ${ }^{28,61}$ As previously discussed, upcoming accreditation standards in the US require increased skill and knowledge-based training of students that will prepare them to effectively and confidently design and implement wellness programs. ${ }^{53}$ A recent study by Antworth and Maffeo investigated the knowledge and comfort level of pharmacy students in the US when assessing patient BMI and counseling on lifestyle modification. ${ }^{62}$ Student accuracy in self-assessment of BMI was approximately $75 \%$ for first- to third-year students (range 73.3\%-75.6\%). Additionally, students' comfort level 
in counseling patients, assessed using a Likert scale, was inversely related to BMI; student ability to counsel on these topics was not discussed. Although the study was limited to one college of pharmacy and did not assess counseling skill, the results suggest that increased training of students in counseling about lifestyle modification in various patient populations appears necessary in order to improve comfort level.

\section{Patient preference and comfort level}

Limitations to pharmacist-led wellness and weight-loss programs also stem from patient needs, attitudes, and knowledge. ${ }^{63-68}$ For example, female consumers of pharmacy services in England were approached by researchers in the community pharmacy setting and asked to complete a questionnaire about general health, previous weight-loss experiences, and ideal weight-loss program. ${ }^{63}$ Respondents were generally comfortable with the idea of receiving weight-loss information from a pharmacist, but only $39 \%$ of those surveyed would select a pharmacist as an ideal provider of services, with physicians, dieticians, and exercise consultants ranked higher in preference. However, participants were as likely to prefer either a physician office or a pharmacy as an ideal setting for the location of treatment services. In contrast, a cross-sectional questionnaire-based study in Scotland $(n=1,236)$ explored patient perceptions of pharmacy-based weight management services. ${ }^{67}$ Top concerns included lack of awareness of the availability of health services through the pharmacy, privacy concerns, lack of comfort in discussing weight loss with pharmacy staff, and perceived lack of pharmacist knowledge.

A survey of patients at five US community chain pharmacies assessed patient knowledge of obesity and obesity-related risks and interest in pharmacy-based weight management services. ${ }^{68}$ Only $35 \%$ of respondents were interested in pharmacy-based services and only $13 \%$ were willing to pay for services out of pocket. This study was relatively limited in the number of respondents $(n=97)$, which represented a response rate of only $11.8 \%$ of the total invited participants and potentially limited the generalizability of the results. However, the results suggest that some patient populations may have reservations about participating in a pharmacy-based weight-loss program.

An online, cross-sectional survey of pharmacy consumers in Australia $(n=403)$ sought to determine patient preferences for weight management services. ${ }^{65}$ Most respondents had never approached a pharmacist for weight-loss advice and cited distrust of pharmacist motivations and conflict of interest as a concern (eg, motive to sell products).
Additionally, respondents perceived pharmacists as lacking in expertise or availability due to time constraints. Interestingly, though, respondents who had sought advice from a pharmacist in the past were more likely to be willing to pay for pharmacist services in the future. This result suggests that marketing of pharmacist weight-loss or lifestyle management services to increase patient awareness of their availability may be beneficial to improving participation by patients, as suggested previously. ${ }^{64}$

\section{Pharmacy business models}

Pharmacists are generally regarded as one of the most trustworthy health care professionals. In a 2013 Gallup poll, pharmacists placed in the top three of the public's most trusted professions for the eleventh year in a row, with $70 \%$ of respondents ranking pharmacists as having high or very high honesty and ethical standards. ${ }^{69}$ However, an additional limitation to pharmacist-led wellness counseling and weightloss programs is the potential perception that some patients may have for pharmacist motivations. Gidman et al surveyed a preselected group of users and nonusers of pharmacy services in Scotland $(n=26)$ using a focus group method to determine public trust in extended pharmacy services as compared to services provided by general practitioners. ${ }^{70}$ In general, participants considered pharmacists to be primarily involved in medicine supply, and their awareness of the pharmacist's extended role was low. Participants were also hesitant to trust pharmacists to deliver unfamiliar services, particularly those who were perceived to be at high risk. Additionally, although participants had positive opinions about the accessibility of the pharmacist, they felt that the physical setting for clinical discussion was not conducive to confidentiality such as that obtained in individualized physician appointments. Participants also perceived receipt of clinical counseling by physicians as no cost since it was included in the office visit, whereas the potential for pharmacists to be motivated by product sales produced a mistrust of pharmacy services. Participants also felt that there was a hierarchy in medicine, in which pharmacist's interventions were dictated strictly by the physician. The study concluded that pharmacist-led services are undermined by lack of public trust and knowledge of pharmacist roles and educational background. Similar barriers might be found in other countries in which pharmacy and medicine have similar relationships.

In another study, Freeman et al investigated the reasons why consumers do not purchase pharmacy-based disease state management services. ${ }^{64}$ The authors did a post hoc analysis of three previous studies completed within their 
practice relating to asthma, dyslipidemia, and diabetes services. Overall, 554 patients were asked to participate in one of the studies, with 376 (67.9\%) declining to pay for the service. Motivational data for reasons participants declined to pay were collected from 297 patients, with ten patients commenting on their reasons. On average across the three studies, $37.5 \%$ of patients cited financial burden as a reason for declining the service. However, duplication of the service as it was provided by other health care providers $(30.3 \%)$ or a perception that the service was unnecessary (17.4\%) was also cited as a top reason for declining service. Therefore, monetary resources were not the only barrier to implementing pharmacy services. It is important to note that the three studies cited by the authors focused on diseases that are commonly closely managed by physicians and the data may not extrapolate to wellness or weight-loss services offered in pharmacies, especially for patients without other monitored comorbidities.

In a meta-analysis of pharmacist and consumer views of public health services (ie, smoking cessation, health promotion and screenings, weight managements, etc) offered in community pharmacies, the authors found that generally consumers had never been offered public health services. ${ }^{46}$ Some studies showed that a majority of consumers $(>70 \%)$ thought health screening and promotion services were appropriate for the pharmacy setting, although one study in Sweden noted that only $24 \%$ of respondents expected dietary advice in the pharmacy. ${ }^{71}$ Consumers generally had mixed views of pharmacists' ability to perform public health services adequately, depending on the service offered and the country of origin. However, those patients who had received public health services were generally satisfied with the outcome.

\section{Accessibility of unhealthy foods}

Another barrier to pharmacist-led interventions in obesity is the accessibility of unhealthy foods in community-based pharmacies. In an editorial published in the Canadian Pharmacists Journal, the authors make a call to action for pharmacists to join other health care professionals in increasing efforts to prevent chronic disease through restrictions on the marketing of unhealthy foods. ${ }^{72}$ The authors comment that pharmacies must acknowledge potential business and corporate conflicts of interest with patient care and that the profitability of selling unhealthy foods must be balanced against the cost of an unhealthy population. As, first and foremost health care professionals, pharmacists must emphasize patient health issues before business interests. Currently, there is a lack of studies investigating the impact of removal of unhealthy food items from community pharmacies, although the idea has been suggested especially in light of removal of other products considered to cause negative health effects such as tobacco products from some chain pharmacies. ${ }^{73}$

In a recent prospective cohort study based on the National Health and Nutrition Examination Survey data, trends in the effect of added sugar consumption on cardiovascular disease mortality were examined. ${ }^{74}$ The authors noted that individuals who obtained $25 \%$ or more of their calories from added sugar had almost three times the risk of death from cardiovascular disease than those who obtained less than $10 \%$ of their calories from added sugar. The health hazard ratio between the two groups was 1.4-fold higher in patients with a BMI $\geq 25 \mathrm{~kg} / \mathrm{m}^{2}$. Therefore, it would seem plausible that access to unhealthy foods should be limited, especially at a sight with a role in health care and disease state prevention, such as a community pharmacy. Although such a move would likely not have a major effect on obesity as a whole, it would increase the credibility of the health care system and remove a potential conflict of interest that currently limits delivery of effective wellness services.

\section{Conclusion}

The worldwide increase in overweight and obesity is an alarming trend. However, access to care is limited for many patients due to patient inability to participate in treatment services (eg, lack of insurance, limited access to physicians, etc) or limited physician time and resources for providing optimal care. Pharmacists have the foundational knowledge and skills to perform basic physical assessments and point-ofcare testing necessary to identify and counsel patients who are overweight or obese. In addition, with the ease and frequency of accessibility of pharmacists by patients, the pharmacy is well situated to house weight and lifestyle management services. Such services, at this point, tend not to be reimbursable either due to lack of coverage by insurance plans or lack of provider status for pharmacists. However, simple counseling at the point of dispensing could be offered either verbally or via informational leaflets. More structured programs could be offered on a limited basis or as a fee-for-service system. For example, a collaborative service involving a primary care physician, a pharmacist, and potentially other providers such as a dietician would help to distribute workload, provide more holistic patient care, and motivate patients via more frequent contact between physician visits. Several successful models of weight loss or lifestyle management services are presented in this review and can be used as examples for future 
development and implementation of services. Several barriers to implementation of pharmacy-based lifestyle management services are discussed and must be resolved prior to effective implementation of any weight-loss or wellness programs: limited pharmacist expertise, time, and resources as well as patient demand and perception of pharmacist aptitude. In addition, current community pharmacy practice business models, especially those of corporate pharmacy, present a conflict of interest, either perceived or real, between patient care and pharmacist or pharmacy motivation to sell products. In order to overcome these barriers, increased training and certification of pharmacists, changes in the traditional pharmacy business model to utilize pharmacists in patient care services and counseling and minimize dispensatory roles, and increased marketing of pharmacy services to patients are necessary.

\section{Disclosure}

The authors report no conflicts of interest in this work.

\section{References}

1. World Health Organization. Global Database on Body Mass Index. Geneva, Switzerland: World Health Organization; 2014.

2. Ng M, Fleming T, Robinson M, et al. Global, regional, and national prevalence of overweight and obesity in children and adults during 1980-2013: a systematic analysis for the Global Burden of Disease Study 2013. Lancet. 2014;384(9945):766-781.

3. World Health Organization ROfE. Obesity Data and Statistics; 2015. Available from: http://www.euro.who.int/en/health-topics/ noncommunicable-diseases/obesity/data-and-statistics. Accessed May 12, 2014.

4. Flegal KM, Carroll MD, Kit BK, Ogden CL. Prevalence of obesity and trends in the distribution of body mass index among US adults, 1999-2010. JAMA. 2012;307(5):491-497.

5. James W. WHO recognition of the gobal obesity epidemic. Int J Obes (Lond). 2008;32(Suppl 7):S120-S126.

6. Ogden CL, Carroll MD, Curtin LR, McDowell MA, Tabak CJ, Flegal KM. Prevalence of overweight and obesity in the United States, 1999-2004. JAMA. 2006;295(13):1549-1555.

7. Ogden CL, Carroll MD, Kit BK, Flegal KM. Prevalence of obesity in the United States, 2009-2010. NCHS Data Brief. 2012;82:1-8.

8. Ogden CL, Carroll MD, Kit BK, Flegal KM. Prevalence of childhood and adult obesity in the United States, 2011-2012. JAMA. 2014;311(8):806-814.

9. Dobbs R, Sawers C, Thompson F, et al. Overcoming Obesity: An Initial Economic Analysis; 2014. Available from: http://www.mckinsey.com/ insights/economic_studies/how_the_world_could_better_fight_obesity. Accessed November, 2014.

10. Obesity ECoC. European Charter on Counteracting Obesity. WHO European Ministerial Conference on Counteracting Obesity; 2006.

11. Thorpe KE, Ogden L, Galactionova K. Weighty Matters: How Obesity Drives Poor Health and Health Spending in the US Washington, DC: National Business Group on Health; 2009.

12. Wang YC, McPherson K, Marsh T, Gortmaker SL, Brown M. Health and economic burden of the projected obesity trends in the USA and the UK. Lancet. 2011;378(9793):815-825.

13. Brown KA, Simpson ER. The link between obesity and breast cancer risk: epidemiological evidence. In: Brown KA, Simpson ER, editors. Obesity and Breast Cancer. New York, NY: Springer; 2014:5-10.
14. World Health Organization. 10 Facts on Obesity; 2015. www.who.int/ features/factfiles/obesity/facts/en/index1.html. Accessed January 29, 2015.

15. Centers for Disease Control and Prevention. Recommended community strategies and measurements to prevent obesity in the United States. MMWR Recomm Rep. 2009;58(RR-7):1-30.

16. Gortmaker SL, Swinburn BA, Levy D, et al. Changing the future of obesity: science, policy, and action. Lancet. 2011;378(9793):838-847.

17. World Health Organization. Global Action Plan for the Prevention and Control of Non-Communicable Diseases 2013-2020. Geneva, Switzerland: World Health Organization; 2013.

18. ASHP therapeutic position statement on the safe use of pharmacotherapy for obesity management in adults. Developed by the ASHP Commission on Therapeutics and approved by the ASHP Board of Directors on April 23, 2001. Am J Health Syst Pharm. 2001;58:1645-1655.

19. Berringer R, Shibley MC, Cary CC, Pugh CB, Powers PA, Rafi JA. Outcomes of a community pharmacy-based diabetes monitoring program. J Am Pharm Assoc. 1999;39(6):791-797.

20. Bluml BM, McKenney JM, Cziraky MJ. Pharmaceutical care services and results in project ImPACT: hyperlipidemia. J Am Pharm Assoc. 2000;40(2):157-165.

21. Mayer JA, Slymen DJ, Eckhardt L, et al. Skin cancer prevention counseling by pharmacists: specific outcomes of an intervention trial. Cancer Detect Prev. 1998;22(4):367-375.

22. Tsuyuki RT, Johnson JA, Teo KK, et al. Study of cardiovascular risk intervention by pharmacists (SCRIP): a randomized trial design of the effect of a community pharmacist intervention program on serum cholesterol risk. Ann Pharmacother. 1999;33(9):910-919.

23. Calis KA, Hutchison LC, Elliott ME, et al; American College of Clinical Pharmacy. Healthy People 2010: challenges, opportunities, and a call to action for America's pharmacists. Pharmacotherapy. 2004;24(9):1241-1294.

24. Um IS, Armour C, Krass I, Gill T, Chaar BB. Weight management in community pharmacy: what do the experts think? Int J Clin Pharm. 2013;35(3):447-454.

25. Ahrens RA, Hower M, Best AM. Effects of weight reduction interventions by community pharmacists. J Am Pharm Assoc. 2003;43(5):583-589.

26. Boardman HF, Avery AJ. Effectiveness of a community pharmacy weight management programme. Int J Clin Pharm. 2014;36(4):800-806.

27. Chisholm-Burns MA, Kim Lee J, Spivey CA, et al. US pharmacists' effect as team members on patient care: systematic review and metaanalyses. Med Care. 2010;48(10):923-933.

28. Harmon M, Pogge E, Boomershine V. Evaluation of a pharmacist-led, 6-month weight loss program in obese patients. $J$ Am Pharm Assoc. 2014;54(3):302-307.

29. Jaques LSJ, T.; Schafer, J.; McClain, S.; Chin, J. Decision memo for intensive behavioral therapy for obesity. In: Services CfMaM, ed; 2011.

30. Lloyd KB, Thrower MR, Walters NB, Krueger KP, Stamm PL, Evans RL. Implementation of a weight management pharmaceutical care service. Ann Pharmacother. 2007;41(2):185-192.

31. Malone M, Alger-Mayer SA. Pharmacist intervention enhances adherence to orlistat therapy. Ann Pharmacother. 2003;37(11):1598-1602.

32. Malone M, Alger-Mayer SA, Anderson DA. The lifestyle challenge program: a multidisciplinary approach to weight management. Ann Pharmacother. 2005;39(12):2015-2020.

33. Morrison D, McLoone P, Brosnahan N, McCombie L, Smith A, Gordon J. A community pharmacy weight management programme: an evaluation of effectiveness. BMC Public Health. 2013;13:282.

34. Thomas MH, Goode JV. Development and implementation of a pharmacist-delivered Medicare annual wellness visit at a family practice office. J Am Pharm Assoc. 2014;54(4):427-434.

35. Kellow N. Evaluation of a rural community pharmacy-based Waist Management Project: bringing the program to the people. Aust J Prim Health. 2011;17(1):16-22.

36. Lenz TL. Therapeutic lifestyle changes and pharmaceutical care in the treatment of dyslipidemias in adults. $J$ Am Pharm Assoc. 2005;45(4):492-499. quiz 500-492. 
37. Lenz TL, Stading JA. Lifestyle modification counseling of patients with dyslipidemias by pharmacists and other health professionals. J Am Pharm Assoc. 2005;45(6):709-713.

38. Santschi V, Chiolero A, Paradis G, Colosimo AL, Burnand B. Pharmacist interventions to improve cardiovascular disease risk factors in diabetes: a systematic review and meta-analysis of randomized controlled trials. Diabetes Care. 2012;35(12):2706-2717.

39. Paulos CP, Nygren CE, Celedon C, Carcamo CA. Impact of a pharmaceutical care program in a community pharmacy on patients with dyslipidemia. Ann Pharmacother. 2005;39(5):939-943.

40. Stading JA, Herrmann J, Walters R, Destache C, Chock A. Impact of a pharmacist intervention on diabetes patients in an ambulatory setting. Diabetes Spectr. 2009;22(4):241-246.

41. DiDonato KL, May JR, Lindsey CC. Impact of wellness coaching and monitoring services provided in a community pharmacy. J Am Pharm Assoc. 2013;53(1):14-21.

42. Expert Panel on Detection, Evaluation, and Treatment of High Blood Cholesterol in Adults. Executive summary of the third report of the national cholesterol education program (NCEP) expert panel on detection, evaluation, and treatment of high blood cholesterol in adults (adult treatment panel III). JAMA. 2001;285(19):2486-2497.

43. John EJ, Vavra T, Farris K, et al. Workplace-based cardiovascular risk management by community pharmacists: impact on blood pressure, lipid levels, and weight. Pharmacotherapy. 2006;26(10):1511-1517.

44. Awad A, Waheedi M. Community pharmacists role in obesity treatment in Kuwait: a cross-sectional study. BMC Public Health. 2012;12:863.

45. Dastani HB, Brown CM, O’Donnell DC. Combating the obesity epidemic: community pharmacists' counseling on obesity management. Ann Pharmacother. 2004;38(11):1800-1804.

46. Eades CE, Ferguson JS, O'Carroll RE. Public health in community pharmacy: a systematic review of pharmacist and consumer views. BMC Public Health. 2011;11:582.

47. Fakih SH, Marriott JL, Hussainy SY. A national mailed-survey exploring weight management services across Australian community pharmacies. Res Social Adm Pharm. 2012;8:e36.

48. O’Donnell DC, Brown CM, Dastani HB. Barriers to counseling patients with obesity: a study of Texas community pharmacists. J Am Pharm Assoc. 2006;46(4):465-471.

49. Um IS, Armour C, Krass I, Gill T, Chaar BB. Managing obesity in pharmacy: the Australian experience. Pharm World Sci. 2010;32(6):711-720.

50. Newlands RS, Watson MC, Lee AJ. The provision of current and future Healthy Weight Management (HWM) services from community pharmacies: a survey of community pharmacists' attitudes, practice and future possibilities. Int J Pharm Pract. 2011;19(2):106-114.

51. Lenz TL, Monaghan MS, Hetterman EA. Therapeutic lifestyle strategies taught in US Pharmacy Schools. Prev Chronic Dis. 2007;4(4):A96.

52. Accreditation Council for Pharmacy Education. Accreditation Standards and Guidelines for the Professional Program in Pharmacy Leading to the Doctor of Pharmacy Degree. Chicago, IL: Accreditation Council for Pharmacy Education; 2006.

53. Accreditation Council for Pharmacy Education. Accreditation Standards and Key Elements for the Professional Program in Pharmacy Leading to the Doctor of Pharmacy Degree. Chicago, IL: Accreditation Council for Pharmacy Education; 2015.

54. Sarayani A, Rashidian A, Gholami K, Torkamandi H, Javadi M. Efficacy of continuing education in improving pharmacists' competencies for providing weight management service: three-arm randomized controlled trial. J Contin Educ Health Prof. 2012;32(3):163-173.

55. Frederick J. With its pharmacists moving out front, Walgreens boosts role of technicians. Drug Store News. 2013.
56. Lin AC, Jang R, Sedani D, Thomas S, Barker KN, Flynn EA. Re-engineering a pharmacy work system and layout to facilitate patient counseling. Am J Health Syst Pharm. 1996;53(13):1558-1564.

57. Schommer JC, Pedersen CA, Gaither CA, Doucette WR, Kreling DH, Mott DA. Pharmacists' desired and actual times in work activities: evidence of gaps from the 2004 National Pharmacist Workforce Study. J Am Pharm Assoc. 2006;46(3):340-347.

58. Schommer JC, Pedersen CA, Doucette WR, Gaither CA, Mott DA. Community pharmacists' work activities in the United States during 2000. J Am Pharm Assoc. 2002;42(3):399-406.

59. Oh Y, McCombs JS, Cheng RA, Johnson KA. Pharmacist time requirements for counseling in an outpatient pharmacy. Am J Health Syst Pharm. 2002;59(23):2346-2355.

60. Savage IT. Time for customer contact in pharmacies with and without a dispensing technician. Int J Pharm Pract. 1995;3(4):193-199.

61. Anderson AS, Goode JV. Engaging students in wellness and disease prevention services. Am J Pharm Educ. 2006;70(2):40.

62. Antworth A, Maffeo C. Pharmacy student self-perception of weight and relationship to counseling patients on lifestyle modification. Am J Pharm Educ. 2014;78(2):35.

63. Fakih S, Marriott JL, Boardman H, Anderson C, Hussainy SY. Comparing women pharmacy consumers' experiences with weight loss treatment in Victoria and Nottingham: a cross-sectional study. BMC Public Health. 2014;14:662.

64. Freeman P, Jones M, Blumenschein K. It's not just the money: why consumers do not purchase pharmacist-provided services. Pharmacol Pharm. 2014;5:570-576.

65. Um IS, Armour C, Krass I, Gill T, Chaar BB. Consumer perspectives about weight management services in a community pharmacy setting in NSW, Australia. Health Expect. 2014;17(4):579-592.

66. Ezlina U, Jalaludin J. Public preferences of weigh loss methods and community pharmacists' assistance in weight management. Int J Pharm. 2014;4(4):67-73

67. Weidmann AE, Cunningham S, Gray G, Hansford D, Bermano G, Stewart D. Views of the Scottish general public on community pharmacy weight management services: international implications. Int $J$ Clin Pharm. 2012;34(2):389-397.

68. O’Neal KS, Crosby KM. Patients' perceptions of a pharmacist-managed weight management clinic in a community setting. Res Social Adm Pharm. 2013;9(1):129-136.

69. Simone A. Pharmacists among most widely trusted professionals, Gallup poll finds. Pharm Times. 2013.

70. Gidman W, Ward P, McGregor L. Understanding public trust in services provided by community pharmacists relative to those provided by general practitioners: a qualitative study. BMJ Open. 2012;2(3):e000939.

71. Larsson EC, Viberg N, Vernby A, Nordmark J, Stalsby-Lundborg C. Health information, an area for competition in Swedish pharmacies. Pharm Pract. 2008;6(2):74-78.

72. Houle S, Rosenthal MM, Campbell NRC, Duhaney T, Tsuyuki RT. Why pharmacists should care about the marketing of unhealthy foods: increasing our role in public health policy. Can Pharm J. 2014;147(1):4-7.

73. After tobacco, should CVS next take sugary drinks and snacks off its shelves? Available from: http://nycfoodpolicy.org/tobacco-cvs-nexttake-sugary-drinks-snacks-shelves/.

74. Yang Q, Zhang Z, Gregg EW, Flanders WD, Merritt R, Hu FB. Added sugar intake and cardiovascular diseases mortality among US adults. JAMA Intern Med. 2014;174(4):516-524. 
Integrated Pharmacy Research and Practice

Dovepress

\section{Publish your work in this journal}

Integrated Pharmacy Research and Practice is an international, peer-reviewed, open access, online journal, publishing original research, reports, reviews and commentaries on all areas of academic and professional pharmacy practice. This journal aims to represent the academic output of pharmacists and pharmacy practice with particular focus on integrated care. All papers are carefully

peer reviewed to ensure the highest standards as well as ensuring that we are informing and stimulating pharmaceutical professionals. The manuscript management system is completely online and includes a very quick and fair peer-review system, which is all easy to use. Visit http://www.dovepress. com/testimonials.php to read real quotes from published authors.

Submit your manuscript here: http://www.dovepress.com/integrated-pharmacy-research-and-practice-journal 